gene EU-Sekundärrecht impliziert auf der Basis der Prinzipien der Entsorgungsautarkie und der Nähe gerade die Statuierung von Uberlassungspflichten und auch die $\mathrm{Zu}-$ weisung an einheimische Anlagen. Bedenken erweckt die Verhältnismäßigkeit einer Beschränkung der Warenverkehrsfreiheit. Insoweit kann aber Art. 106 Abs. 2 AEUV eingreifen, der eine Erfüllbarkeit von gemeinwohlbezogenen Sonderpflichten zu wirtschaftlich tragbaren Bedin- gungen ermöglicht. Daher kann auch die Auslastung eines dafür erforderlichen Netzes regionaler Entsorgungsanlagen hierfür herangezogen werden. Das deckt sich mit der EuGH-Judikatur zu Art. 16 Abfallrahmenrichtlinie und den darin enthaltenen Prinzipien der Entsorgungsautarkie und der Nähe auch für gemischte Siedlungsabfälle aus privaten Haushalten und mit ihnen eingesammelte gewerbliche Abfälle.

\title{
Baumschutz und Befreiung nach altem und neuem Recht
}

\author{
Anmerkung zum Urteil des VGH München v. 25.4.2012 - 14 B 10.1750, in diesem Heft Seite 862 \\ Peter Fischer-Hüftle
}

Es geht hier um eine Verpflichtungsklage auf Genehmigung zum Fällen eines geschützten Baumes. Maßgebend ist dabei die Rechtslage im Zeitpunkt der gerichtlichen Entscheidung. Mögliche Rechtsgrundlagen für eine Abweichung vom Fällverbot sind zum einen $₫ 4$ Abs. $1 \mathrm{BSchV}$, der auf die Befreiungsregelung des Art. 49 BayNatSchG a.F. verweist und vier Beispiele nennt, zum anderen $₫ 67$ Abs. 1 BNatSchG 2009 (Befreiung), der als konkurrierende Bundesvorschrift am 1.3.2010 an die Stelle des Art. 49 BayNatSchG getreten ist.

Der VGH München prüft zunächst die Voraussetzungen der Befreiung nach Maßgabe des $₫ 4$ Abs. 1 BSchV und dabei den zentralen Begriff der „nicht beabsichtigten Härte“. Er lehnt sie ab, u.a. mit der Begründung, es müsse sich um eine grundstücksbezogene Härte handeln, was hier nicht der Fall sei. $\$ 67$ Abs. 1 BNatSchG erwähnt das Gericht zwar, prüft ihn aber nicht als eigenständige Rechtsgrundlage des behaupteten Anspruchs, obwohl dort die - hier allein in Betracht kommende - Befreiungsvoraussetzung als „unzumutbare Belastung" beschrieben wird, ein Begriff, der nicht immer zu denselben Ergebnissen führen muss wie der Begriff „,nicht beabsichtigte Härte“. Begründet wird diese Vorgehensweise nicht, sie versteht sich auch nicht von selbst. Dass $₫ 4$ BSchV eine abschließende Regelung der Befreiung trifft und $\$ 67$ BNatSchG daher irrelevant ist, wird man nicht ernstlich behaupten können. Allein aus der vom VGH zu Recht bejahten Fortgeltung der auf altem Recht beruhenden Baumschutzverordnung lässt sich diese Konsequenz jedenfalls nicht ableiten. Vielmehr bedürfte es dann einer Erörterung der Frage, ob die Bezugnahme in $\$ 4$ BSchV auf Art. 49 BayNatSchG a. F. zu einer Fortgeltung dieser außer Kraft getretenen Gesetzesnorm im Kontext der Verordnung führen kann, etwa im Sinne einer statischen Verweisung. Dass es Absicht des Verordnungsgebers war, mit der Verweisung auf die seinerzeit geltende Norm ein von späteren Gesetzesänderungen unabhängiges

Peter Fischer-Hüftle, Rechtsanwalt,

Regensburg, Deutschland
Rechtsregime der Befreiung in der Verordnung zu etablieren, ist aber kaum anzunehmen. Vielmehr dürfte hier nur eine deklaratorische Verweisung vorliegen, die sich mit Außerkrafttreten der Norm erledigt hat. Eine Regelungslücke entsteht dadurch nicht, denn es gilt $\$ 67$ BNatSchG unmittelbar (wie auch schon die Geltung des Art. 49 BayNatSchG a.F. nicht von einer Erwähnung in der Verordnung abhängig war). Die in der Verordnung genannten vier Beispiele einer nicht beabsichtigten Härte passen auch zum neuen Gesetzesbegriff ,unzumutbare Belastung“. Gleich wie man $₫ 4 \mathrm{BSchV}$ beurteilt, kann die Vorschrift jedenfalls nicht die Wirkung haben, dass $\$ 67$ BNatSchG im vorliegenden Fall keine Geltung hat und nicht zu prüfen ist.

Der VGH hätte diese Fragen auch dahinstehen lassen und sich mit einer Prüfung des $\$ 67$ Abs. 1 Satz 1 Nr. 2 BNatSchG begnügen können. Denn auch diese Vorschrift würde der Klage nicht zum Erfolg verhelfen. Gegen das Vorliegen einer unzumutbaren Belastung sprechen dieselben Gründe, mit denen eine nicht beabsichtigte Härte zu Recht verneint wird: Der Kläger hat den Befall seiner beiden Eichen durch den Eichenprozessionsspinner zu spät bekämpft, und in der Umgebung seines Grundstücks befindet sich noch eine größere Anzahl von Eichen, die bei nicht rechtzeitiger Bekämpfung befallen und beim Kläger weiterhin allergische Reaktionen auslösen würden. Auch das Erfordernis der Grundstücksbezogenheit behält im Zusammenhang mit der „unzumutbaren Belastung“ (ebenso wie bisher bei der nicht beabsichtigten Härte) jedenfalls dann Geltung, wenn es sich wie hier um Bestandteile eines Grundstücks handelt, die Gegenstand eines naturschutzrechtlichen Verbots sind. Da sich die von Bäumen ausgehenden Allergene überallhin verbreiten, kann dieser Aspekt des Baumschutzes nicht bezogen auf einzelne Grundstücke, sondern nur generell bei der Abwägung vor Erlass der Verordnung gewürdigt werden. Die allergieauslösende Wirkung geschützter Bäume ist dabei dem allgemeinen Lebensrisiko zuzuordnen und hindert die Unterschutzstellung nicht. Davon abgesehen wären die Eigentümer solcher Bäume durch das bloße Fehlen eines öffentlich-rechtlichen Schutzes nicht dazu verpflichtet, sie zu beseitigen, um die Allergene zu vermindern. 